\title{
Architecture of a Management Information System for Farmers
}

\author{
E. Šilerová1, K. Heynnyeová ${ }^{2}$ J. Jarolímek ${ }^{1}$ \\ ${ }^{1}$ Faculty of Economics and Management, Czech University of Life Sciences Prague, Czech Republic \\ ${ }^{2}$ Faculty of Economics and Mangement, Slovak University of Agriculture Nitra, Slovak Republic
}

\begin{abstract}
In view of growing importance of data, information and knowledge in companies has become very actual issue of the quality of their processing through the information system modules. Using of modules of the management information systems for qualified analyzes conducted over primary data stored in companies in the Czech Republic is not too widespread. The aim of this article is based on a long-term investigation conducted to analyze the situation and propose for agricultural holdings architecture management information system for farmers to support their decision-making activities.
\end{abstract}

\section{Keywords}

Data, information, knowledge, information systems, management, architecture of information systems.

Šilerová, E., Heynnyeová, K. and Jarolímek, J. (2016) “Architecture of a Management Information System for Farmers", AGRIS on-line Papers in Economics and Informatics, Vol. 8, No. 4, pp. 163 - 169. ISSN 1804-1930, DOI 10.7160/aol.2016.080415.

\section{Introduction}

Data, information and knowledge in the last two decades become one of the most important corporate resources. The process of their processing and further use in decision-making nowadays is impossible imagine without high-quality information systems and in particular without the modules that support management decisions. In the most of companies are stored in the databases a huge capacity of data and information. These data and information have for company further added value only if they will also further used and if on the basis of their processing will be performed qualified decisions. The volumes of data stored in databases regularly every year increase several times (statistics show that the annual growth enterprise database is equal to 5-year increase in previous years). Stored primary data and information in databases have only registered character. With these data is necessary to continue to working. They became significant when they are connected to knowledge and wisdom. Knowledge and wisdom in most of cases are not stored in information systems. Owner of knowledge as well as wisdom, are people who are in the company and are able to use and work with company databases and information.

Therefore, for highly qualified decisions is necessary to connect knowledge of employees with the data and information stored in company databases. It is the primary company databases which provide the basis for the formation of databases on the tactical level management. Data and information stored in these databases have already been processed according to the requirements of managers, according to their requirements of outputs. Lack of data and information has a negative impact on the entire decision-making process.

The most important factor of every company in today's economic environment is the ability to process information with high precision. For the processing of data and information is important to use technological innovation that the company becoming more competitive. The importance of farmer's information systems (FMIS) is highly respected in this regard. For instance, Lewis (1998) stated that "innovative tools for managing computer and databases have the potential to increase the quantity and quality of information available for decision making." Just few FMIS use technologies of information processing with the option of using the Internet and all of its added value. Currently, in the Czech Republic there is not such an information system available at all. For example, Zeman company offers only the basic modules of information systems -accounting, wages, materials storage, herd turnover, land registration. Making use of these modules is not supporting decision-making or economic modelling, it is used only to store data. 
The data and information in agricultural holdings arise in all segments, however, their integration is almost zero. The data and information are stored in modules of individual segments of the company and they are mostly used for the further processing only regions where the data originated and where it is stored. Therefore, nowadays senior managers gain information throughout the entire agriculture holding at one place very problematic. This is the currently situation in the Czech Republic. The same situation is in other European countries, as stated Nikkila et al. (2010). FMIS has little decision support functionality, using enterprise data and increasing competitiveness.

Until now the research data usage in agricultural holdings primarily aimed at supporting decisions of computational biological models - for instance crop yield forecasts (Australian project focused on decision support functions in connection with the cultivation of wheat - a system called WHEATMAN) for field operations - planning machines planning the consumption of fertilizers, determining the driving speed depending on predicted revenue, soil nutrient stocks and other technological decisions. Use of systems for data processing and informed decisions for nitrate fertilization deals Fiez et al. (1994).

In recent years, the development of automated systems in agriculture gained increased interest, which led to that the research teams devoted to exploring the development of rational and adaptable systems based on a behavioral approach (Sørensen et al., 2010). Combined use of new communication technologies, sensor systems, GPS systems, geographic systems (GIS) enable the development of new systems for growing and harvesting crops (Slaughter et al., 2008). Robotic applications in agriculture, forestry and horticulture have been developed for different activities - dairy robots, robots for growing tomatoes, strawberries.

The precision agriculture is technically and computationally more difficult than traditional agriculture. This complexity results not only from the practical implementation of precise measurement and precise applications, but also work with the information system, which is a central element in the system of precise agriculture. For traditional FMIS is usually output (report) is made in the form of documents and paper forms.

The structure of the current output reports is predefined and the farmer gets the assembly at regular intervals, in which changes only the data. There is no change in the structure of demand for outputs, nor is it feasible. Changing the structure of the output report is a long-term matter and often is associated with a considerable financial burden on businesses. Precise agriculture allows the structuring of output on-line and is realized with much greater precision on individual properties, stables, equipment, employees, directly depending on the requirements of managers. Principles of development of information systems solves Stail and Reynolds (2011).

In 2009, the EU funded project that will bring a new model and a prototype of a new information system for management of agricultural enterprises. In a study of the project Sørensen et al. (2011) defined and analyzed boundaries of the system and identified relevant decision-making processes FMIS. Related studies Lawson et al. (2011) solves potential benefit for the introduction of agricultural information management systems in Germany, Greece, Denmark and Finland. From The results of the study show that "More than $40 \%$ of companies surveyed in Germany, Denmark and Finland were unsure about usefulness of information systems." (Lawson et al, 2011). However, the authors also concluded that is needed more research utilization of innovative technologies and benefits information system. The research project FutureFarm continues by identification of content "process" information flow model entities that represent the use of information processes, and "information" entities that represent data elements (Sorensen et al., 2011). Collection of data for the system of agricultural management is done, for example, Steinberger et al. (2009) by software architecture for the management of agricultural information systems in the field of precision agriculture is engaged Nikkilä et al. (2010), who addresses the integration of individual sections of the agricultural company and utilization for control processes. The importance of using data from information systems in agriculture solves Demiryurek. (2010). Solved issue with long-term investigations Heynnyeyova and Depes (2010), Šmída (2007), Welch and Welch (2007) and are jointly managed and consulted

Via declared benefits FMIS is this type of research in the Czech Republic only sporadic. There is still no coherent information system specializing in agricultural production on crop and livestock production with technical services, economics and management, to support decision-making of farmers. 


\section{Materials and methods}

The article was prepared on the basis of scientific methods - analysis, synthesis, induction and deduction. The theoretical part was created by using secondary sources, the study of scientific and professional articles. The analyzed data are obtained by carrying out regular surveys in selected sample of 186 companies. The survey is doing by polling personal managers who directly use data and information from the company information system for their decisions. Was elected structure of companies, which corresponds to the representation of companies in the national structure. In a sample of companies investigation was carried out, which specifies the types of outputs from management information system in the company. Based on the investigation and identify the situation and the need for agricultural holdings will be designed architecture management module that will creates the conditions for improve the management of the whole agriculture holding.

\section{Results and discussion}

However, the economic benefits of precision agriculture is still unknown. Positive effects can be caused by being precisely specify the cost of the entire production process. Figure 1 shows that precision agriculture requires accurate information, highly skilled human capital and local applications - factors that create an ideal source of data for further processing and evaluation of economic efficiency. That means a guarantee that the used amount of input exactly corresponds to cost. Seeds, fertilizers and pesticides are applied exactly according to soil quality. In the same way can modify the soil depending on the exact space conditions. Using GPS positioning system can precisely map the fields imbalance and also in response to induce application technique to be responsive to the variability of fields and allow the most effective use of all resources.

The most valuable of these process are stored data and information. In the crop production, farmers can work with data relating precisely to each plot for each plant species to each tractor to each worker. Based on available technology can be listed data monitor almost online. The manager can monitor the movement of the machine and the effectiveness of the monitored device. These are the data obtained from the activities related directly to work on individual plots - tillage, seeding, crop protection, harvesting. Therefore it is possible to calculate precisely and accurately the cost per unit. The obtained data, which are stored in data storage, are a source of further qualitative shift in land use - the data can be used directly in the design of solutions to crop rotation, determine how the special use of the principle of precision agriculture on the whole company efficiency. Growing measures is useful for better comparison to convert into a graphic form and matching them with the proposed silvicultural treatments. Problems of processing and use of data and information in agriculture is also engaged Šimek et al. (2015).

If a farmer focuses a lot of information to all land plots, yet does not practice the principles of precision farming. He has to know how to further deal with this amount of information that are stored throughout the whole year, and all the monitored years. It is necessary to make sense of stored data, the data must be converted to a specific operational solutions. Nowadays is successful only that one who can produce not only economically, but mostly sells very effectively. Therefore it is important to work with the data that was established on the agricultural holding. This requires using of high-quality software. Impact on quality of management decisions has using of wellprepared companies data. Currently it is possible to using tools for work with stored data - using the Business Intelligence software. The Business Intelligence software helps to make better use of corporate resources. With Business Intelligence (BI) applications can get our own data, quickly and easily find out the results of business activities - production, sales, circulation material. At present

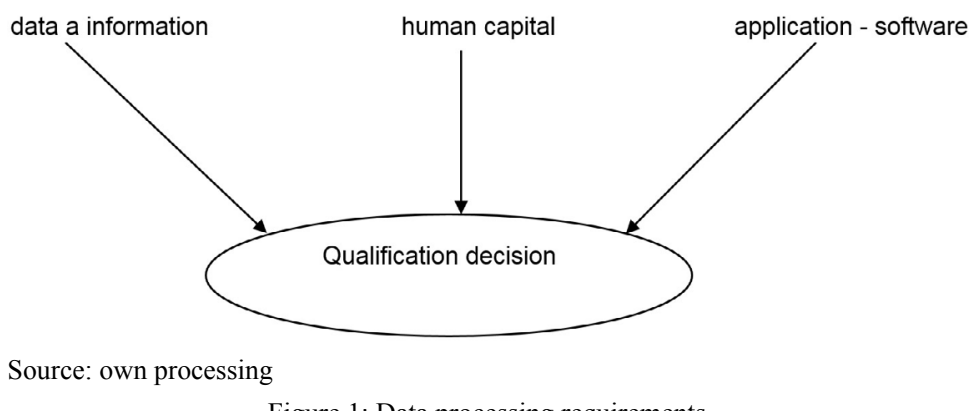

Figure 1: Data processing requirements. 
is counting with absolute course to access individual reports and with on-line access to the requested reports. To a greater extent, ensures the accuracy and quality of outputs and BI tools also no longer just the prerogative of senior management, but it is also used by ordinary users increasingly.

Since 2006 is regularly carry out investigations in a sample of companies - among selected companies included companies from the entire production and processing spectrum, including agricultural holdings, range of services, public administration. It is observed how the data and information for decision making in companies acquired. A total of 168 companies is monitored. Four options of acquisition were selected Regular reports, outputs from corporate databases into Excel, meetings and software Business Intelligence. From the following graph is clear that there are still data and information in most companies acquired by regular reports. Based on carried out investigations, we can say that regular reports are still in $50 \%$ forwarded to senior managers in printed form. In the last three years we have seen increased usage of software type BI that allows very well, carry over corporate data analysis and further with acquired data working.

In monitored 8 years was the largest decline of outputs provided in an environment of periodic reports, which are mostly represented outputs in printed form. In this form of output in the monitored period there was a decrease by $23 \%$. On the contrary the highest increase occurred in the using of business intelligence software more than tripled $-233 \%$. However, there are still remain regular reports in printed form as most widely used output from an information system for further decisions.
Investigation showed that the use of on-line output gradually increases. The strength of on-line outputs for decision-making processes is high and needed.

The situation in the agricultural sector is very different. Outputs for decision is very difficult to establish because the modules are not integrated and outputs work only the heads of department - an agronomist with the data in crop production, livestock specialist in livestock production. Modules in agricultural holdings are not integrated, and therefore can not access the data for the entire company uniform. Respondents who answered to question „Usage of data and information for further work" positively, ie. they using the data for other activities, to implement the principles of precise agriculture and they work with data in creating model situations. Very often they use only the data stored in the database and process the data by hand on paper. $45 \%$ of all respondents use data to further improve the quality of tillage, fertilization, sowing and harvesting. Basically everyone using connection to GPS and according to data about the status of land are being made these further activities. Only $15 \%$ of respondents in relation to acquired data modified crop rotations. Data about stock of nutrients in the soil and knowledge requirements of each crop and the market price of crops may affect crop rotation. In the Czech Republic in relation to growing market prices of grain sown area is already exceeds $60 \%$ of the total area sown farmland. In such cases the use of the principles of precision agriculture has a big impact on the amount of income and opportunities for economic monitoring of individual plots.

Only 4\% of respondents continue to work with the data that gain when using applications related with the precise agriculture. They form

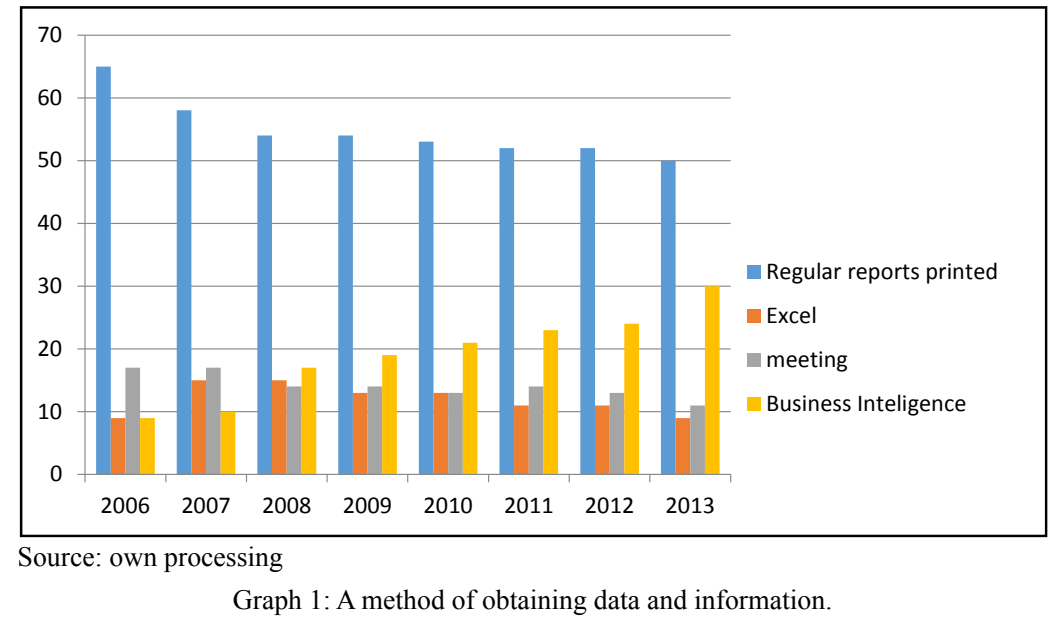


on basic of acquired data about the quality individual property, the economic situation of the company and the expected development of commodity price analysis of the current situation and forecasts for the coming years. Which crops will be the most economical and particularly in relation to the quality of land to cultivate. Unfortunately, the software that would allow carrying out these activities firms does not have. In many cases, they using the options of available spreadsheet (Excel) and often data sourcing again, they do not have the option of using stored data. There is thus a multiple data redundancy.

It is necessary to design an integrated database and then work with these data for the entire company. It is important to link data from crop production, livestock production with other data in the company - sales, economic data, and data from the field of human resources. Appropriate data sharing leads to a qualitatively higher utilization of all resources, resulting in reducing costs, increasing revenues and precision agriculture and also improve environmental quality.

On the Figure 2 is a draft of creation an integrated database. In a single database or individual interconnected databases are stored data from individual processes in the company. Stored data will be further used by appropriate tools
- for instance through Business Intelligence software. Knowledge of management staff in the field (in our case, agriculture) and also their ability to work with stored data creates long-term competitive advantage. You can use the software that will be created for working directly with the proposed data - this option will be more expensive, but for many users easier. Inquiries carried over enterprise data will already created. The user will only learn using of those queries (functions). The second option is a software solution with the type of database environment, or spreadsheet. Employees directly create queries in the selected software according to specific requirements. Selecting the appropriate options will be affected:

1. financial resources of the enterprise

2. human factor - knowledge in the field, the ability to control and use ICT

The advantage of the database created is the ability to access, according to the user and his access rights to the selected data. Can be generated models (Figure 3) when creating the prediction in plant production, animal husbandry, trade, economics, human resources, entire company - using business data (internal) and for modelling efficiency is the best process with external data (for instance expected market prices, sales volumes and others).

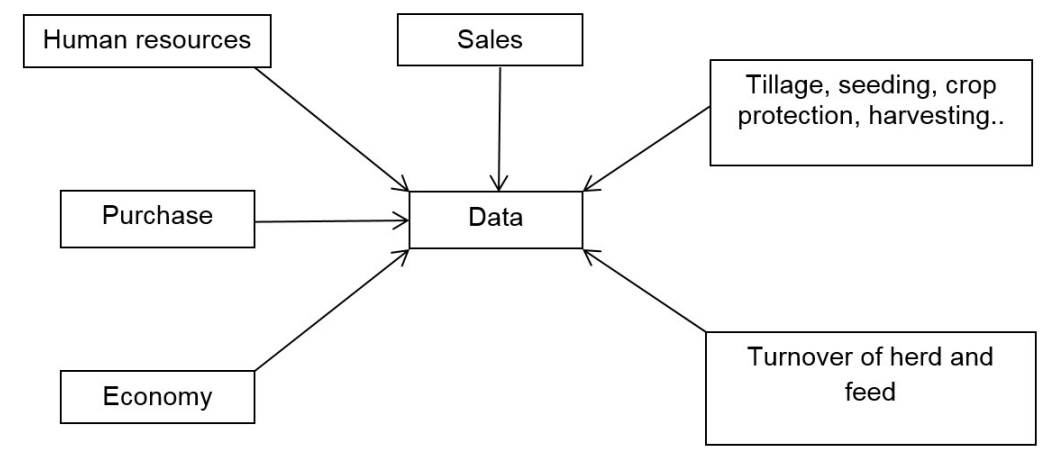

Source: own processing

Figure 2: Draft integrated database.

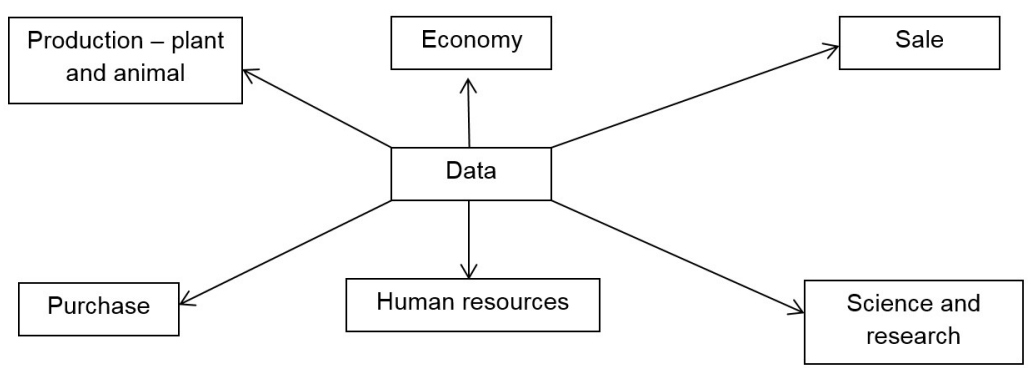

Source: own processing

Figure 3: Prediction models. 
In the current economic environment, an important aspect of improving competitiveness is not only use the latest scientific findings, but also involved to the activities.

\section{Conclusion}

Creating of architecture has to be closely associated with the creation of an information strategy. Data and information become one of the most valuable corporate resources. Their use, importance and influence on the further development of the company are fully affected by the ability of managers to use all the data and information (internal and external). The quality of the information strategy is determined by the team's ability to define information needs. By creating a database that will individual modules of information system use, has to be clearly defined its individual components. By creating the database has to be a team representative of each corporate department, to create high-quality base of data that will become an essential starting point for the creation of reports for further decisions. Fiez, Lewis and Sørensen focus mainly on the use of the principles of precision agriculture in crop and livestock production, processing technology throughout agriculture. For the creation of information strategies and architectures can be used and the conclusions Dohnal and Pour (1999) and Kourdi (2009).

In this environment of rapid technological changes, agricultural development, economic situation, acceptance of strategy should be based on the option with the best value $\mathrm{x}$ power (variant of creating the highest quality reporting according to actual requirement).Agriculture is becoming a knowledge-intensive sector, where what employees will know (what data and information acquire) is a key factor in profitability. Ownership of tools of precision agriculture has its place in business and information strategy, but it is not the only option for increasing competitiveness. More important element is the involvement of the tools of precision agriculture throughout the corporate chain of production - sale - employees - the economy. Precision agriculture will fully support the development of the company, if will be done the interconnection in all parts of the company and it is only possible for the situation when we model the stored data from all ongoing activities of the company. Architecture design makes this possible specifically for agriculture holding.

\section{Acknowledgements}

The results and knowledge included herein have been obtained owing to support from the Internal grant agency of the Faculty of Economics and Management, Czech University of Life Sciences in Prague, grant no. 20161028, “Assessment of quality, usability and accessibility of electronic services from the perspective of small and middle sized enterprises in the agrarian sector".

\section{Corresponding author:}

Ing. Edita Šilerová, Ph.D.

Department of Information Technologies, Faculty of Economics and Management

Czech University of Life Sciences Prague, Kamýcká 129, Prague 6-Suchdol, 165 21, Czech Republic

E-mail: silerova@pef.czu.cz

\section{References}

[1] Dohnal, J. and Pour, J. (1999) “Řizení podniku a ř́zení IS/IT v informační společnosti” (Business management and management of IS/IT in information company, in Czech), University of Economics, Prague, 118 p. ISBN 80-7079-023-7.

[2] Demiryurek, K. (2010): „Information systems and communication networks for agriculture and rural people“, Agricultural Economics, Vol. 56, No. 5, p. 209-214. ISSN: 0139570X.

[3] Fiez, T. E., Baird C. M. and William L. P. (1994) “Assessment of Spatially Variable Nitrogen Fertilizer Management in Winter Wheat", Journal of Production Agriculture. Vol. 7. No. 1, pp. 86- 93.

[4] Heynnyeyova, K. and Depes, P. (2010) "Analysis of the exploitation of information and communication technologies in the agri-food sector companies", Agricultural Economics, Vol. 56, No. 9, pp. 403 - 408. ISSN 0139-570X. 
[5] Nikkila, R., Seilonen, I. and Koskinen, K. (2010) "Software architecture for farm management information systems in precision agriculture", Computers and Electronics in Agriculture, Vol. 70 , No. 2, pp. 328-336. ISSN 0168-1699. DOI 10.1016/j.compag.2009.08.013.

[6] Kourdi, J. (2009): „Podniková strategie“ (Business strategy, in Czech), Prague, ComputerPress, a.s., 300 p. ISBN 978-80-251-2725-4.

[7] Lawson, L. G., Pedersen, S. M., Sørensen, C. G., Pesonen, L., Fountas, S., Werner, A., Oudshoorn, F. W., Herold, L., Chatzinikos, T., Kirketerp, I. M. and Blackmore, S. (2011) “A four nation survey of farm information management and advanced farming systems: A descriptive analysis of survey responses". Computers and Electronics in Agriculture, Vol. 77, No.1, pp. 7-20. ISSN 0168-1699. DOI 10.1016/j.compag.2011.03.002.

[8] Lewis, T. (1998) "Evolution of farm management information systems", Computers and Electronics in Agriculture, Vol. 19, No. 3 , pp. 233-248. ISSN 0168-1699. DOI 10.1016/S0168-1699(97)00040-9.

[9] Sørensen, C. G., Fountas, S., Nash, E., Pesonen, L., Bochtis, D., Pedersen, S.M., Basso, B. and Blackmore, S. B. (2010) "Conceptual model of a future farm management information system", Computers and Electronics in Agriculture, Vol . 72, No. 1, pp. 37-47. ISSN 0168-1699. DOI 10.1016/j.compag.2010.02.003.

[10] Sørensen, C. G., Pesonen, L., Bochtis, D. D., Vougioukasc, S. G. and Suomi, P. (2011) "Functional requirements for a future farm management information system", Computers and Electronics in Agriculture, Vol. 76, No. 2, p. 266-276. ISSN 0168-1699. DOI 10.1016/j.compag.2011.02.005.

[11] Stail, R. and Reynolds, G. (2011) „Fundamentals of Information Systems. Course Technology“, Boston, 458 p. ISBN 978-0840062185.

[12] Steinberger, G., Rothmund, M. and Auernhammer, H. (2009) "Mobile farm equipment as a data source in an agricultural service architecture", Computers and electronics in agriculture, Vol. 65 , No. 2, pp. 238-246. ISSN: 0168-1699. DOI 10.1016/j.compag.2008.10.005.

[13] Šimek, P., Stočes, M., Vaněk, J. and Masner, J. (2015) "Mobile accessibility of information sources in the areas of agriculture, forestry, water management, food industry and rural development". Agrarien Perspectives XXIV. - Global Agribusiness and Rural Economy. Prague, Czech University of Life Sciences Prague, pp. 440 - 446, ISBN 978-80-213-2581-4.

[14] Šmída, F. (2007) “Zavádění a rozvoj procesního ř́zení ve firmě" (Implementation and development of process management in firm, in Czech), GradaPublishing a.s., Prague, 300 p. ISBN 978-80-247-1679-4.

[15] Welch, J. and Welch S. (2007) "Komu podřídit útvar IT?" (To whome IT department should be subordinated?, in Czech), Moderní ř́zení, No. 2, pp. 45-46. ISSN 00268720. 